This item was submitted to Loughborough's Research Repository by the author.

Items in Figshare are protected by copyright, with all rights reserved, unless otherwise indicated.

\title{
Information overload: the differences that age makes
}

PLEASE CITE THE PUBLISHED VERSION

http://dx.doi.org/10.1177/0961000614566341

\section{PUBLISHER}

SAGE Publications

\section{VERSION}

SMUR (Submitted Manuscript Under Review)

\section{PUBLISHER STATEMENT}

This work is made available according to the conditions of the Creative Commons Attribution-NonCommercialNoDerivatives 4.0 International (CC BY-NC-ND 4.0) licence. Full details of this licence are available at: https://creativecommons.org/licenses/by-nc-nd/4.0/

\section{LICENCE}

CC BY-NC-ND 4.0

\section{REPOSITORY RECORD}

Benselin, Jennifer C., and Gillian Ragsdell. 2019. "Information Overload: The Differences That Age Makes". figshare. https://hdl.handle.net/2134/16765. 


\section{Introduction}

The notion of information overload has a long history. In fact, Bawden et al. (1999) attribute the writer of Ecclesiastes as making the first link between an excess of information and a reduction in efficiency with the statement that "of making many books there is no end; and much study is a weariness of the flesh" (Ecclesiastes, XII, 12). Gutenberg's invention of the printing press circa 1540 (Hemp, 2009) exacerbated the situation with unprecedented amounts of information becoming available. However, Noyes and Thomas (1995) believe that information overload only became a major problem towards the end of the 19th century. In more recent times, Bush (1945: 1) highlighted the problem of information overload although he did not term it as such. Instead, he expressed it as: "there is increased evidence that we are being bogged down [by] a growing mountain of research". The concept of excessive information impairing performance was probably first labelled as information overload' in the 1960s. Levy (2008) cites Meier (1962), Gross (1962), Boulding (1966) and Ackoff (1967) as having used the phrase, albeit with no accompanying definition.

Information overload has become an increasingly popular area of study, especially since the invention of the internet and World Wide Web. Quantity of information is rapidly increasing and the means of accessing it are more varied and easier to use. Thus far, there has been no investigation into the relationships between age, perception of and chance of suffering from, information overload. This study aimed to ascertain whether such a link exists and identify the implications for future generations.

\section{Background literature}

Since the first use of the phrase in the 1960s (Levy, 2008), definitions of information overload have changed very little. Early understanding of the term, as expressed by Jacoby (1977) and Malhotra et al. (1982), focussed on humans having too much information and only a finite ability to process it. In a similar vein, Rudd and Rudd (1986: 305) described information load as being "that amount of information actually acquired by a processing system" with the corollary that information overload is the remainder of information available but unable to be processed. In fact, Bawden et al. (1999: 250) found that there is no single definition of information overload but sum it up as occurring when "information received becomes a hindrance rather than a help when the information is potentially useful". More recently, Jackson and Farzaneh (2012: 524) reviewed the literature over the years and drew similar conclusions. 
Of course the context of information overload has changed. In the 1970s and 1980s the focus was on information overload related to the quantity of journal articles and consumer choice (Jacoby, 1977, 1984; Malhotra et al., 1982; Michalos, 1974; Latane, 1978). Later studies have had to contend with the influx of information from advancing technology. For example, email overload (Waller and Ragsdell 2012; Soucek and Moser 2010), mobile communications (Allen and Shoard, 2005) wiki systems (Stickel et al., 2008), and the impact of organisational information overload on productivity, worker health and economic cost (Meglio and Kleiner, 1990; Eppler and Mengis, 2004) have been the focus of more recent studies. As technology advanced, bringing with it "the printed book, the periodical magazine or journal, the abstracting journal, and the computer" (Bawden et al., 1999: 250), the assumption was that the occurrence of information overload would increase. This study identified new perceptions of information overload and corresponding new understanding of the impact of the phenomena.

Levy (2008: 47) gave the cause of information overload as "the recent explosion of information technologies" with Karvalics (2007) claiming that, by the mid-2000s, the majority of the world was part of an information society. "In a crowded 'information society', ... the amount of information being created every two days is equivalent to that created from the dawn of civilisation until year 2003" (Jackson and Farzaneh, 2012: 524). Between 2000 and 2012, the number of internet users has risen by 500 per cent and now includes over a third of the world's population (34\%, Miniwatts Marketing Group, 2013). Berghal (1997: 20) believes that the primary cause of information overload on the internet comes from it simultaneously trying to fulfil two roles - "being both a private and a public information and communication medium".

The search engine was the first attempt to deal with information overload on the internet (Berghal, 1997). Referred to as the "gate-keeper to the world's information" (Elwert, 2013: 1) search engines deliver massive, sometimes overwhelming, amounts of information but only at the users' desire. However, an abundance of information does not automatically lead to quality of information. It is difficult to judge the veracity of information on the internet; as Berghal (1997: 20) says, it is "credibility and value-neutral" and "picking the wheat from the chaff can be ... time consuming and arduous" (Reuters, 2000: 5).

Emails are commonly cited as a cause of overload; the result has been a growing body of research into email overload (Szóstek, 2011; Soucek and Moser, 2010) perhaps furthered by the fact that "e-mails have an immediacy that is hard to ignore" (Reeves, 2002: 1) and are an inherent part of most workplaces. Likewise, mobile technologies present an inability to turn 
off, whether due to personal desire or outside pressures, leading them to be called "electronic tagging devices" (Reeves, 2002). While there is not much research on the impact of mobile technologies on information overload (Allen and Shoard, 2005), it seems likely that, with all the capabilities they have in terms of connectivity and access to information, smartphones are becoming the medium by which we suffer internet and technology based information overload.

Technology is both a principal cause and main solution to information overload in today's society (Elwert, 2013). Allen and Shoard (2005: 227) maintain that it is not technology itself that causes information overload but "its use (or rather, its misuse)". Technology helps us to select and filter information (Wellmon, 2012) but without the skills to maximise the potential offered it becomes a "two-edged sword" (Bawden et al. 2000: 154).

The psychological and physical consequences of information overload are numerous and can have severe implications at the individual, societal and organisational levels. Basex research (Spira and Burke, 2009) indicates how big a problem it can be, with costs of around $\$ 900$ billion each year to the US economy. Stress is the most common effect felt by sufferers of information overload. Defined as "the adverse reaction people have to excessive pressures or other types of demand placed on them at work", workplace stress can lead to anxiety, depression, high blood pressure, insulin resistance and heart disease (HSE, 2013). Lewis (1996) found that two thirds of managers had suffered from information overload related stress and loss of job satisfaction, while one third of managers suffered from ill health as a consequence of stress.

The abundance of information available has begun changing the way we interact with it, "the deep reading that came naturally has become a struggle" (Carr, 2010: 5). We now skim and scroll and move between pages: behaviour that Rowlands et al. (2008) called 'horizontal information seeking'. Our interaction with information has changed on a psychological level, a "...continuous partial attention, a focus on being 'in touch' and 'connected' which results in stress, and attention deficit trait" (Bawden and Robinson, 2009: 183). This behaviour is compounded by today's social media savvy society with blogs, Twitter and Facebook condensing information to a more palatable length (Wellmon, 2012: 68).

The effects of information overload can spill over into leisure time affecting a person's work/life balance and causing a negative impact on their general wellbeing (Tildine, 1999). Too much information and choice can leave a person feeling overwhelmed, confused (Rudd and Rudd, 1986) and unable to make adequate decisions: an effect that has not changed significantly since the first studies were carried out. Researchers from Jacoby in the 1970s to 
Bawden and Robinson in 2009 have found similar consequences of suffering information overload. Lewis' (1996) "...paralysis of analysis" and "a decrement in the quality of decisionmaker performance" (Jacoby, 1977: 572) are two of the main consequences to remain consistent over time.

Since the first use of the term information overload in the 1960s (Levy, 2008) up until the present day, a review of the literature has shown that definitions of the phrase have not changed and nor have its effects; on the other hand, causes of information overload have expanded over time with the advancement of technology. It is possible that, as instant 24/7 access and demand for information becomes the norm in society, "who knows: maybe someday even I will enjoy swimming in the powerful currents of information that now threaten to pull me under" (Hemp, 2009: 1). No doubt the reaction of future generations to the abundance of information will become an increasingly pertinent question for academics of information and its associated behaviours.

\section{Research methods}

This study was carried out within an interpretivist philosophy and entailed the gathering of both quantitative and qualitative data. Questionnaires, interviews and diaries were selected as the most appropriate research methods for data collection in the knowledge that the use of multiple methods, or triangulation (Bell, 2010), ensured that the most comprehensive results were available.

An online questionnaire was used giving advantages of access to a large and diverse sample of participants, reduced researcher time spent collecting responses and reduced costs (Wright, 2005). Guidance was taken from Frazer and Lawley (2000: 23) with consideration given to the design of the questionnaire; question content, question wording, response format and structure, and layout. In order to ensure validity of the research methods, a pilot study was carried out prior to widespread distribution with participants providing feedback on content, suitability and ease of answering each question, length of time to complete and clarity of instructions.

Forty five completed questionnaires were returned and followed up by five semi structured interviews. Interviews permitted complex answers to be given while introducing new areas of thought and produced a wealth of qualitative data on participants' information habits along with their thoughts and feelings on the topic. The interviews were carried out following a predesigned framework covering areas of interest that emerged from completed questionnaires. Themes included information literacy, characteristics of information and impaired performance. 
Diaries were used to supplement the data gathered through the use of interviews and questionnaires. A diary can help to "identify patterns of behaviour [and] ascribe meanings to actions and events" (Aleszewski, 2006: 37) by allowing people to record their thoughts and feelings towards information overload on a daily basis, and giving them free reign to expand on what they are feeling. Four completed diaries were returned. Participants were given a number of prompts which were aimed at making the diary entries as simple and easy as possible to complete in order to maximise participation and quality of data. Prompts included topics such as their information usage and amount of time spent accessing and using various types of information, whether they suffered from information overload and what the causes and effects of this may have been.

Having considered the different sampling techniques available, a combination of random and convenience sampling was chosen. An email containing the link to the online questionnaire was sent to prospective participants and shared on social network sites. This enabled collection of data from a widely geographically dispersed sample. Due to the initial low number of respondents aged between $41-60$ and $70+$ from the online questionnaire, the researcher approached a number of personal contacts. This also had the benefit of obtaining results from people who do not have access to the internet (a major limitation of using the online questionnaire). Interviewees and diarists were self-selecting based on their willingness to take part by accepting an invitation given at the end of the questionnaire. This method ensured that participants already had some knowledge of the topic being researched and reduced the level of non-response. Table 1 shows the age profiles of participants.

Table 1 - Participant profiles

\begin{tabular}{|c|c|c|c|c|c|c|c|}
\hline $\begin{array}{c}\text { Questionnaire x 45 } \\
\text { participants }\end{array}$ & $18-25$ & $26-30$ & $31-40$ & $41-50$ & $51-60$ & $61-70$ & $70+$ \\
\hline $\begin{array}{c}\text { Number of participants per } \\
\text { age group }\end{array}$ & 6 & 13 & 9 & 3 & 3 & 7 & 4 \\
\hline Interviews x 5 participants & 1 & 1 & 1 & 1 & 1 \\
\hline Diaries x 4 participants & 1 & 1 & 1 & 1 \\
\hline
\end{tabular}

The questionnaire website produced a report containing the data entered online to which the results from the paper copies of questionnaires were added. Once all the completed 
questionnaires were returned the qualitative data obtained from the open ended questions was coded. This involved picking out the themes that emerged from each answer and entering this data into an Excel spread sheet to record frequency of occurrence. The findings from the interviews and diaries were similarly grouped before being combined with the questionnaire results. The findings were written up in a thematic way and provided comparisons and observations about the differences in answers from the different age groups. Descriptive statistics were used throughout.

\section{Findings}

A thematic exploration of the data is presented with each section sharing the results obtained from the questionnaires, diaries and interviews as appropriate. Current and new areas of interest that emerged are analysed while an overview of the responses of people of different ages and careers is offered.

\section{Defining information overload}

This question related to participants' definition of information overload. Figure 1 captures their understanding of the concept.

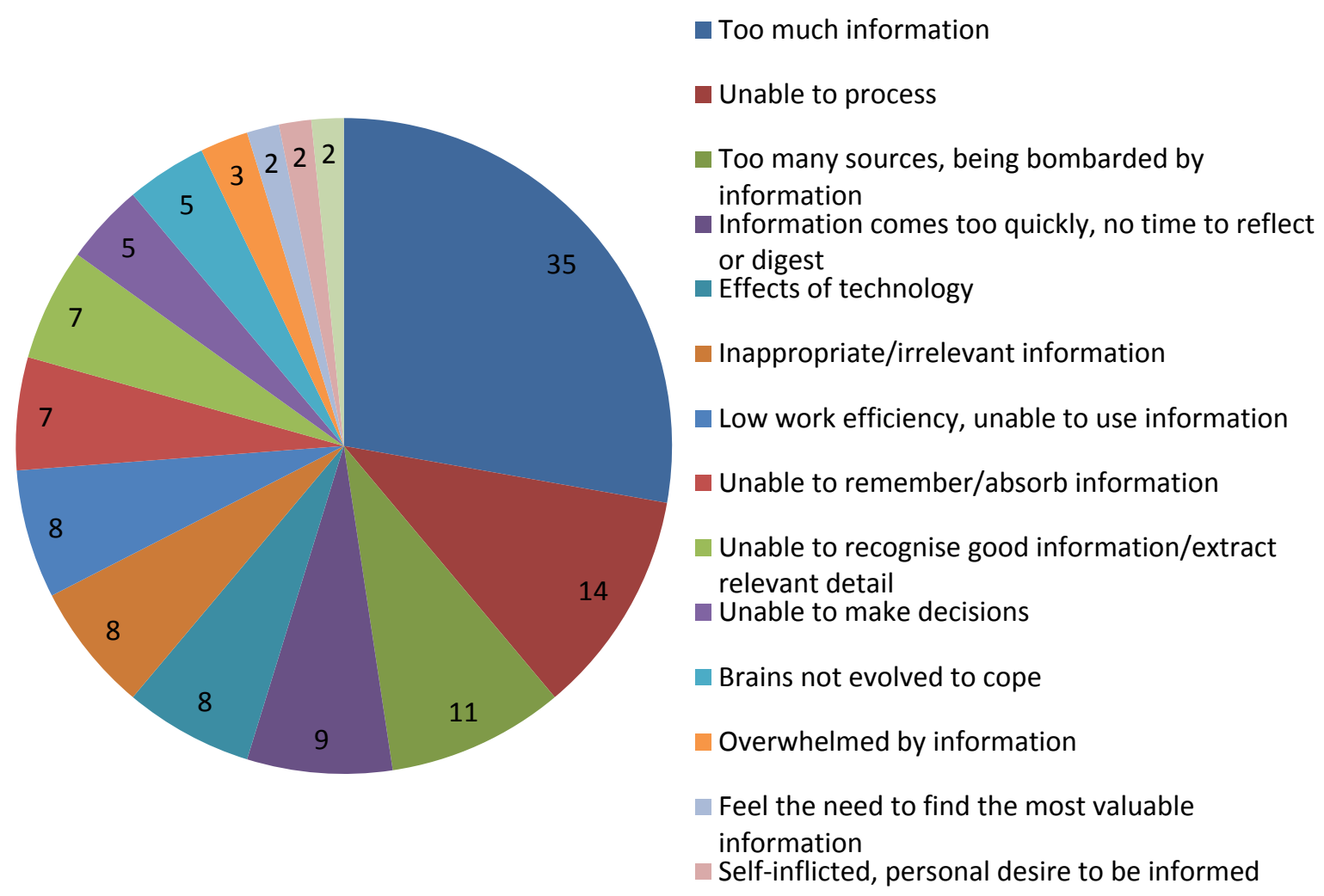

Figure 1- Themes that emerged from questionnaire definitions 
All but two of the questionnaire respondents (aged $31-40$ and $70+$ ) recognised that information overload does not consist simply of 'too much information' and qualified their response with further statements. Psychological consequences featured heavily while eight people discussed technology as a factor in creating information overload.

All five interviewees discussed the issue of too much information and the negative effects that can have on a person's ability to analyse information without confusion. Phrases that can be equated with effects of information overload, such as low work efficiency, inability to make decisions and extract relevant detail, were most commonly cited by those in older age groups. Likewise, the effect of technology was mostly observed by older ages while speed of information and not having time to reflect or absorb was stated by the younger age groups.

\section{Who suffers from information overload and where?}

The overwhelming majority of questionnaire respondents have both heard of information overload and suffered from it. Of the two who had not heard of the phrase, one was a housewife aged $70+$ and the other was in the $41-50$ age group and a community care worker. Of the three working age respondents, of whom none had ever suffered information overload, two work as administrators and the other as a strategic planner (who has previous experience in administration). Throughout the questionnaire these three participants made comments to the effect that information overload is a result of not being able to manage information, that confidence and skills in searching for information are important and that, without these skills, it is easy to become overwhelmed.

Twenty nine of the questionnaire respondents are currently in employment and 'work' is the area where people most commonly feel affected. In a similar way, each of the interviewees claimed to have suffered from information overload with four being most affected at work with volume of emails received being the primary cause.

Diarists were asked to comment on their experiences of information overload and how often they felt it. One diarist has never experienced information overload, and is able to find information quickly and easily. They found that closing Microsoft Outlook on one day aided in progression of other tasks and another diarist commented that they also experienced an increase in productivity after deferring emails to another day. 


\section{Information characteristics}

Participants were asked about their perceptions of the quantity and quality of information that they come into contact with.

In relation to quantity of information, forty four respondents mentioned one or more of the topics in Figure 2 as part of their definition of information overload. All the age groups agreed that too much information can be a cause of overload and this topped the list of causes stated in the questionnaires. Quantity of information did not arise as a topic in any of the diary entries whilst the interviewees were split between believing that, whilst information quantity has remained constant, the ease of accessing it has increased and believing that there is now more information than previously.

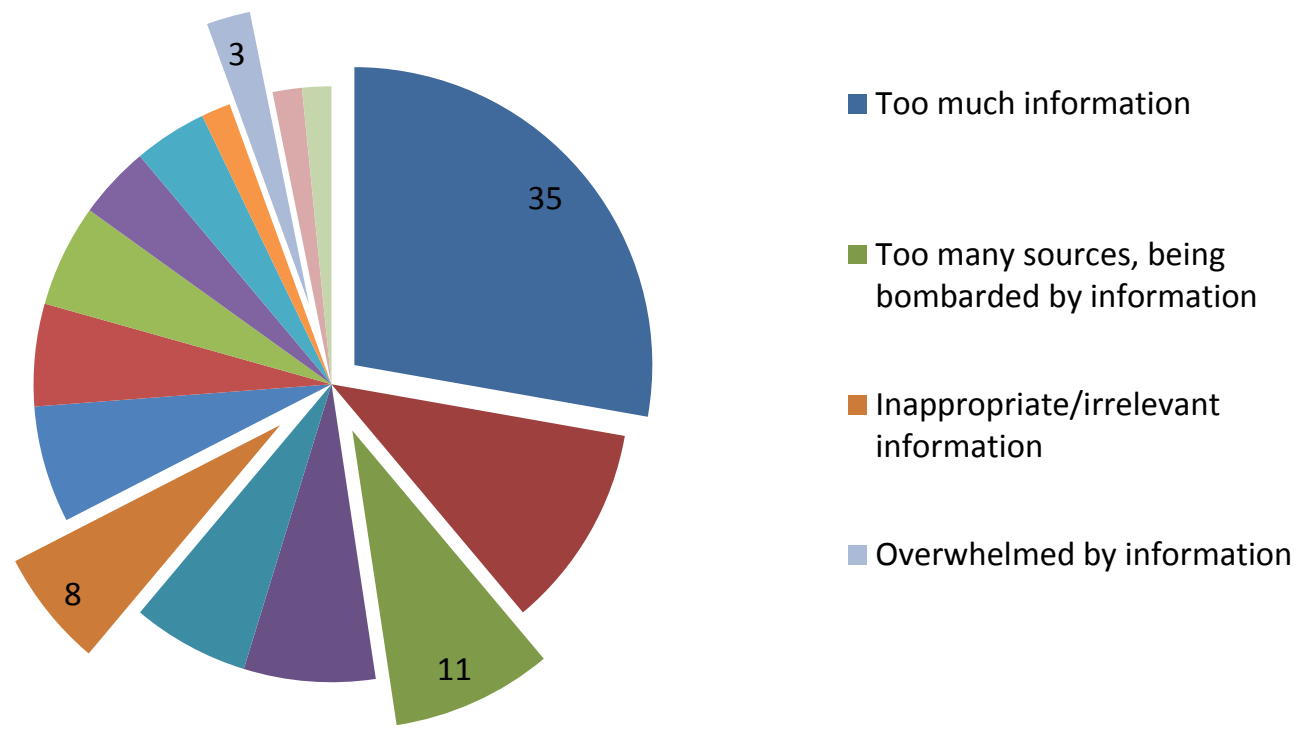

Figure 2 - Current perceptions of quantity of information - extracted from the themes in figure 1

The results of the Likert scale questions about information quantity and its effects are shown in Figure 3. 


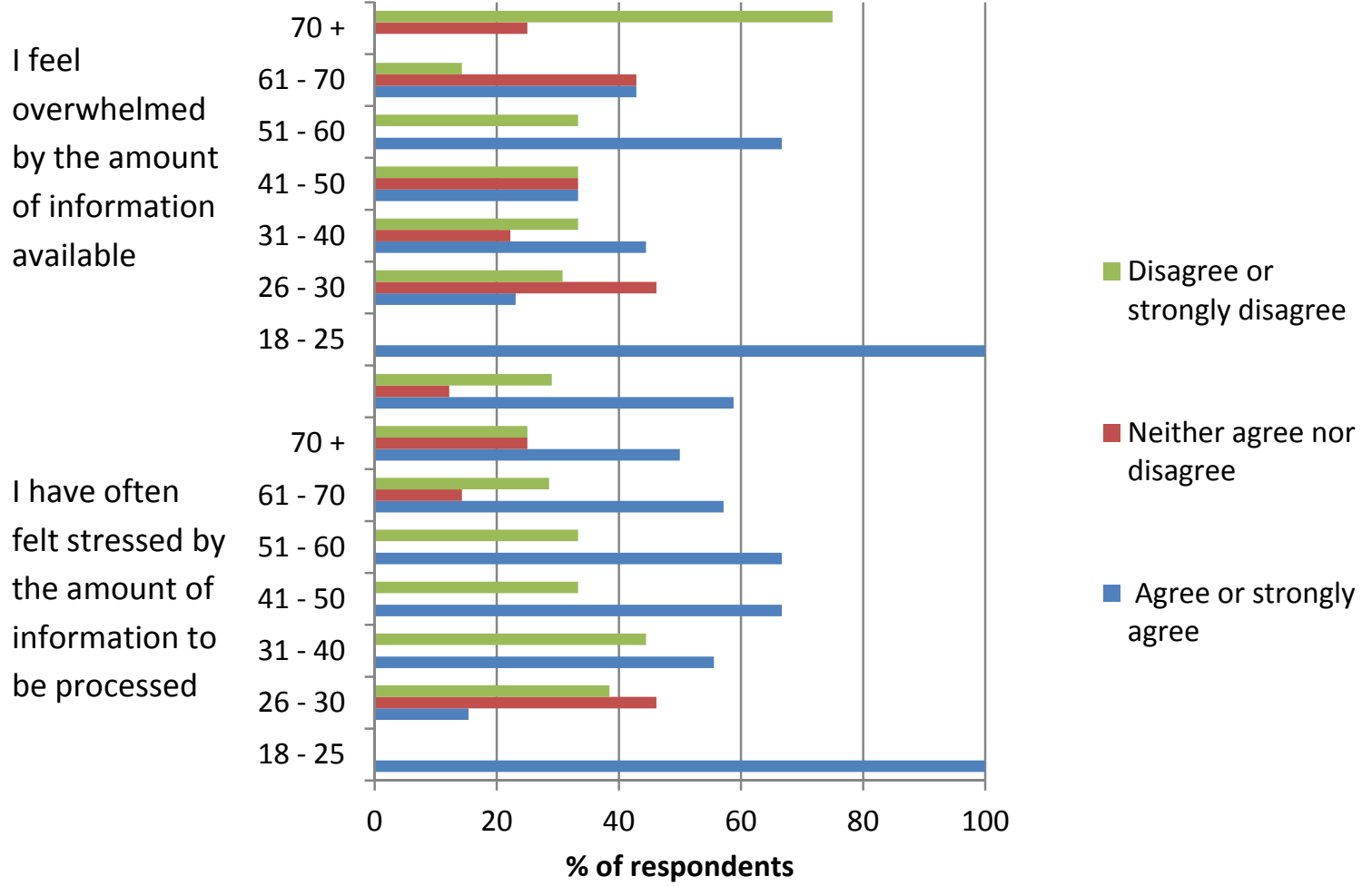

Figure 1 - Impact of quantity of information

Despite the proliferation of responses throughout the questionnaire pertaining to quantity of information, for the first question, with the exception of the youngest and the oldest age groups who are in strong agreement and disagreement respectively, there is no clear trend that emerges. The second question, likewise, has no correlation but a pronounced level of agreement from all the age groups except $26-30$, that they felt overwhelmed and stressed about the amount of information.

When asked whether most information is good quality, twenty five respondents disagreed, only five agreed while no one strongly agreed. There was strong consensus across all the ages that a lot of information available is irrelevant with thirty seven respondents concurring with this statement.

A link between quantity and quality of information was highlighted in the questionnaire:

"Things are more accessible, and quicker to get to, but now everyone can post information the quality has decreased."

Other questionnaire responses included comments on the number of conflicting opinions to be found on the internet and a reduction of trust in both sources and an individual's interpretation of the information. These comments came most frequently from the $26-30$ year olds. 


\title{
Information literacy
}

The terms in Figure 4 are drawn from the open ended questions featured throughout the questionnaire: twenty seven participants cited at least one of the statements given. Ability to manage information was the biggest concern to the $31-40$ age group while the $26-30$ age group was most concerned about remembering or absorbing information.

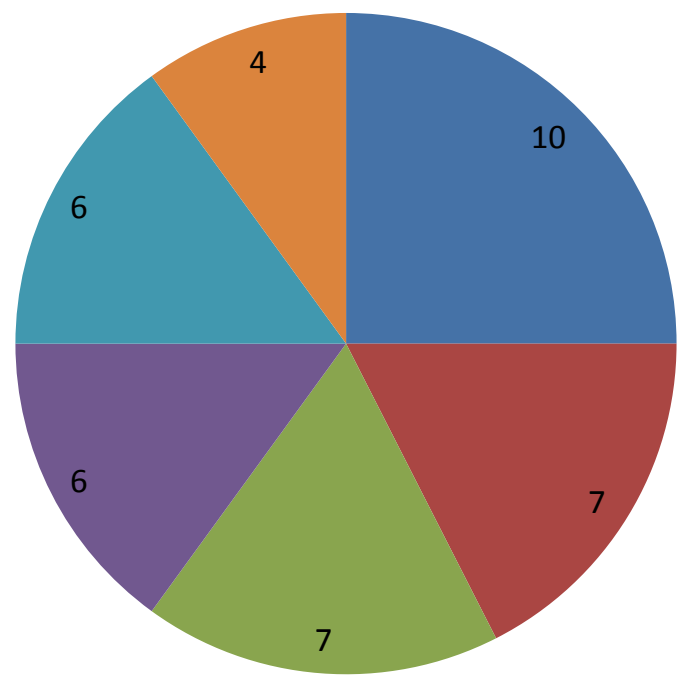

\author{
Ability to manage/filter \\ information \\ Ability to compute/use \\ information \\ Absorb/remember information \\ Accuracy, able to recognise good \\ information \\ - Trust/confidence \\ - Control
}

Figure 4 - Information literacy related responses

All the terms in Figure 4 were cited at least once by a member of the $26-30$ age group making them the most aware of information literacy aspects. Control was cited most often by the 61 - 70 year olds while there was no outstanding concern for any of the remaining ages.

Two of the interviewees stated that improved information literacy skills would aid the general public in avoiding information overload:

"I think it would directly help if you knew how to search for things and be able to find things efficiently ... If they knew more they'd feel it less." Iv3

"I think because information is more readily available, people have learnt the skills,... that empowers them more." Iv5.

Four of the five interviewees believed themselves to be relatively information literate. The fifth interviewee was less sure of their skills stating that it could sometimes take them a while to filter out the information they need and decide if a source was reputable or not. 


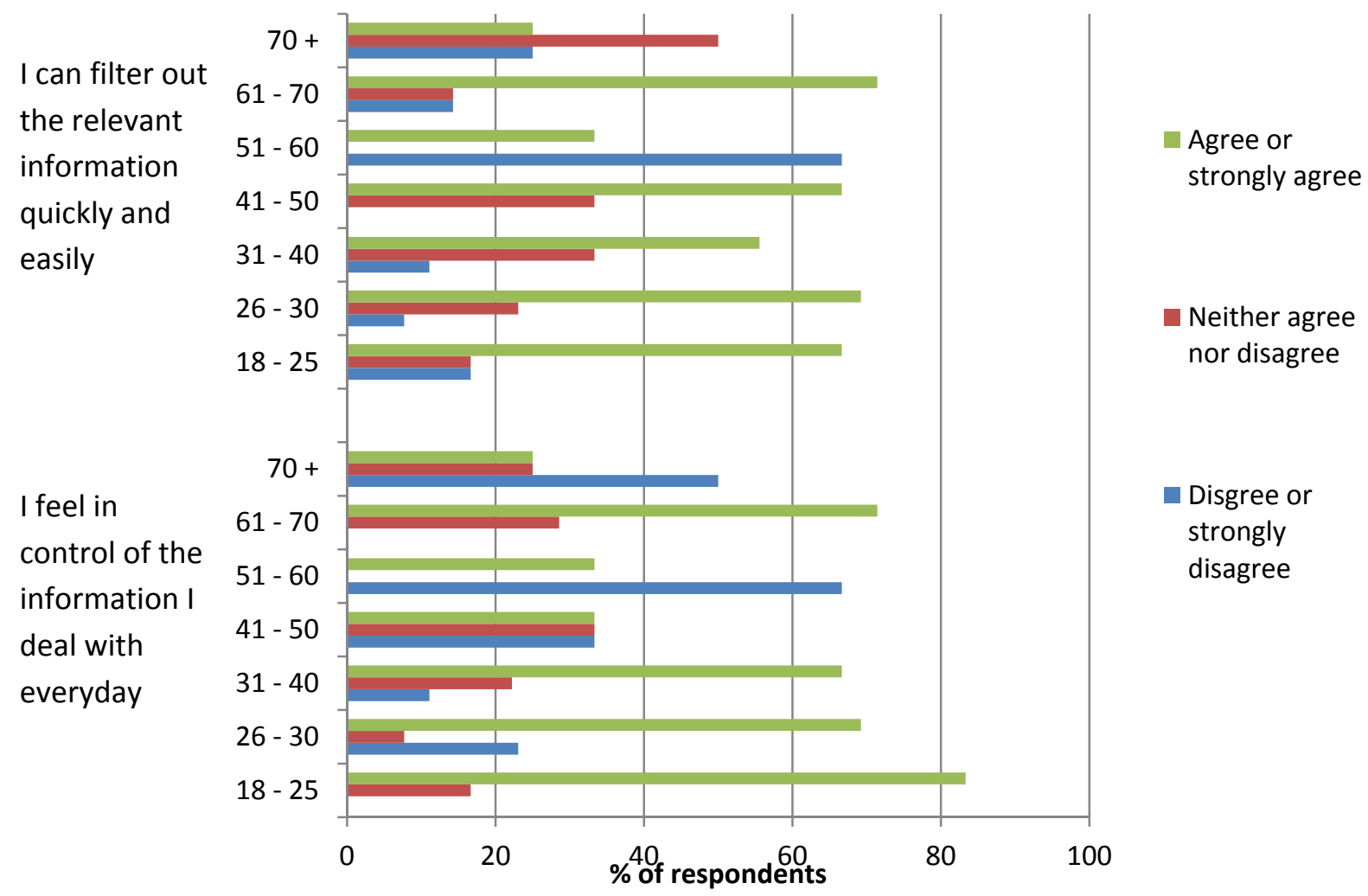

Figure 5 - Likert scale questions on information literacy

An overwhelming majority reacted positively to the first statement in Figure 5 . The $51-60$ age group bucks the trend set by the other ages who, apart from the $70+$ were in overall agreement with this statement. Likewise when asked about control of information, the responses of the $51-60$ and $70+$ age groups were different from the remaining ages. There is no correlation between age and level of agreement.

\section{Impaired performance}

A number of health and performance related issues emerged as effects of information overload. Figure 6 illustrates the most frequently mentioned. 


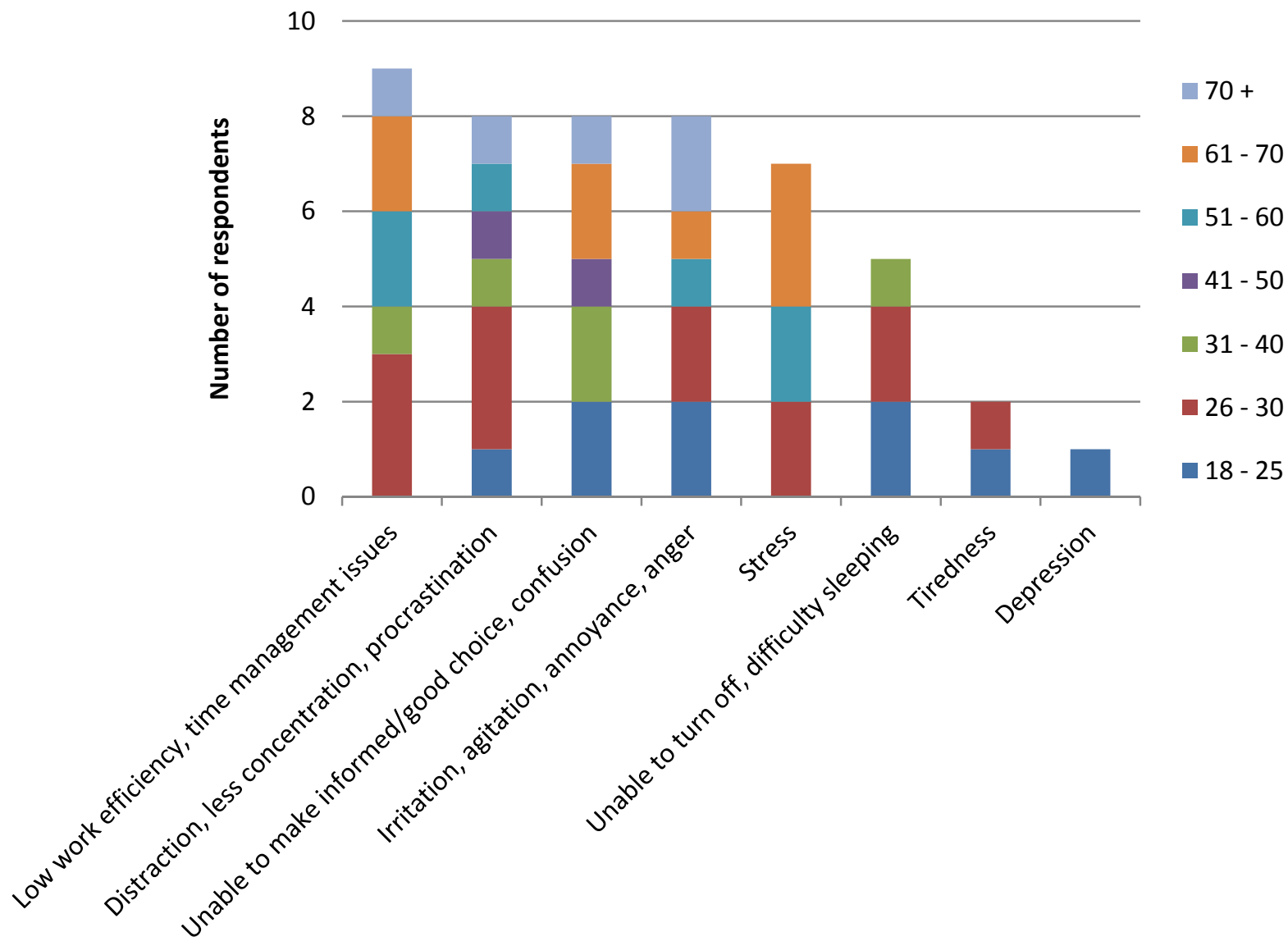

Figure 6 - Effects of information overload

Reduced productivity in the workplace along with time management issues were the top ranked effects, mentioned by most participants. None of the effects was mentioned by people from every age group. 


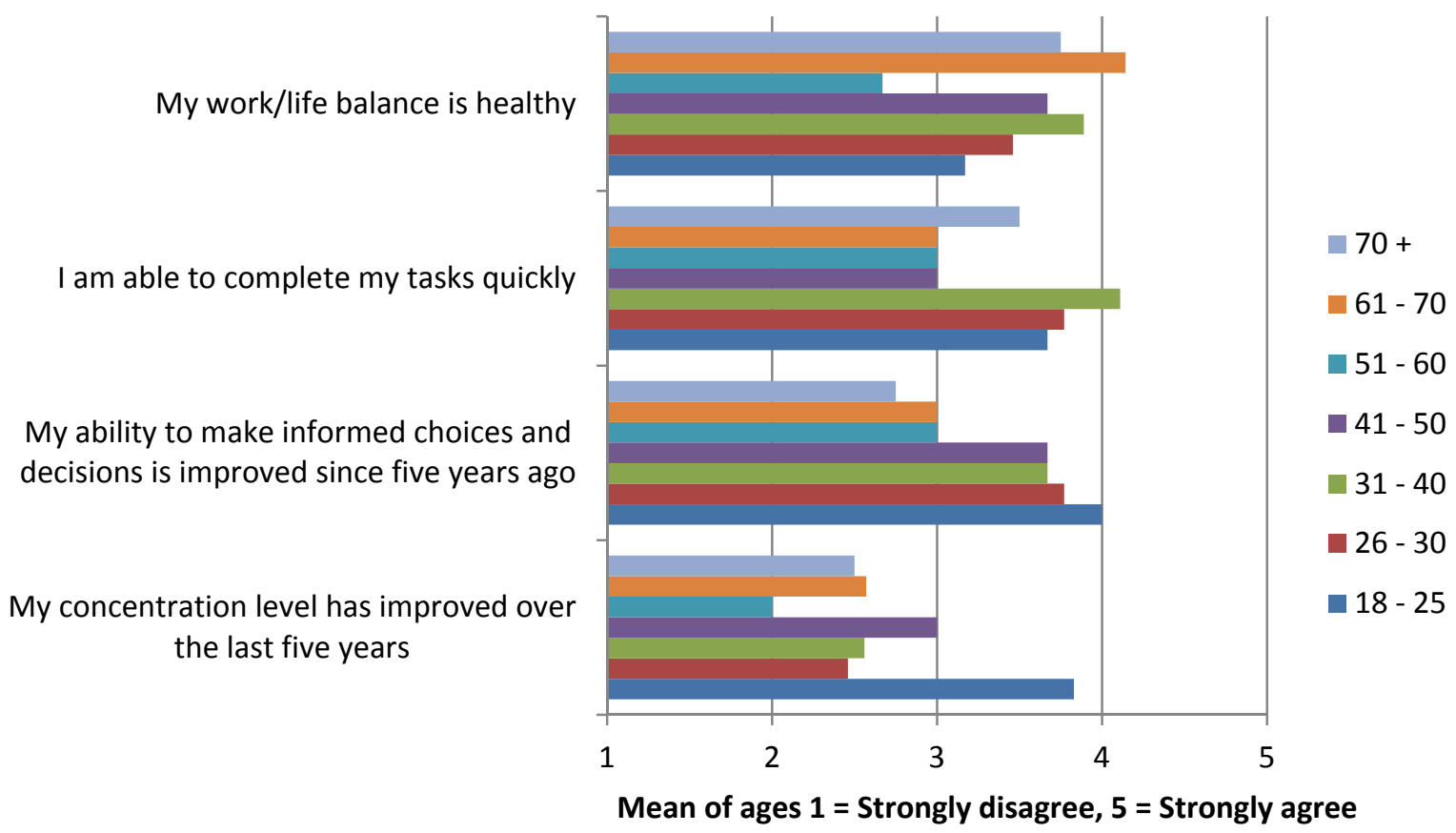

Figure 7 - Likert scale questions on impaired performance

The 18 - 25 year olds were the only age group to feel their concentration had improved in the last five years; the remainder fall more towards disagreeing with this statement. The only age to believe their work/life balance is unhealthy was the 51 - 60 year olds who returned the least, or equal least, agreement to each statement.

Two of the diarists suffered from information overload during the course of the week stating frustration, stress and inability to get on with the job and complete tasks as the main effects suffered. A third diarist also suffered a headache due to information overload and having to make too many decisions. This, along with tiredness, - mentioned once each by the two youngest age groups in the questionnaire - were the only physical reactions highlighted in this study. Psychological effects were mentioned much more often. Altered moods such as anger, depression and irritation came up frequently in the questionnaire and the interviews.

\section{Technology and information usage}

As mentioned earlier, advancements in technology have brought changes in the way that we interact with information. In this section, the types of information sources that participants use and participants' relationship with information are presented.

Technology featured heavily in the top ten information sources used by participants with eight being related to the internet, television or smartphones. Only two - friends and family and colleagues - involve face-to-face contact. One participant found that "communication has become far more about text based interaction rather than actual spoken conversations." 
One of the interviewees had also experienced this; "you can be talking to someone and the phone goes and the first thing you do [is check it]. I wouldn't have done that ten years ago." Additionally, they also found that technology helps them communicate more with their friends but this is to the detriment of face-to-face interactions.

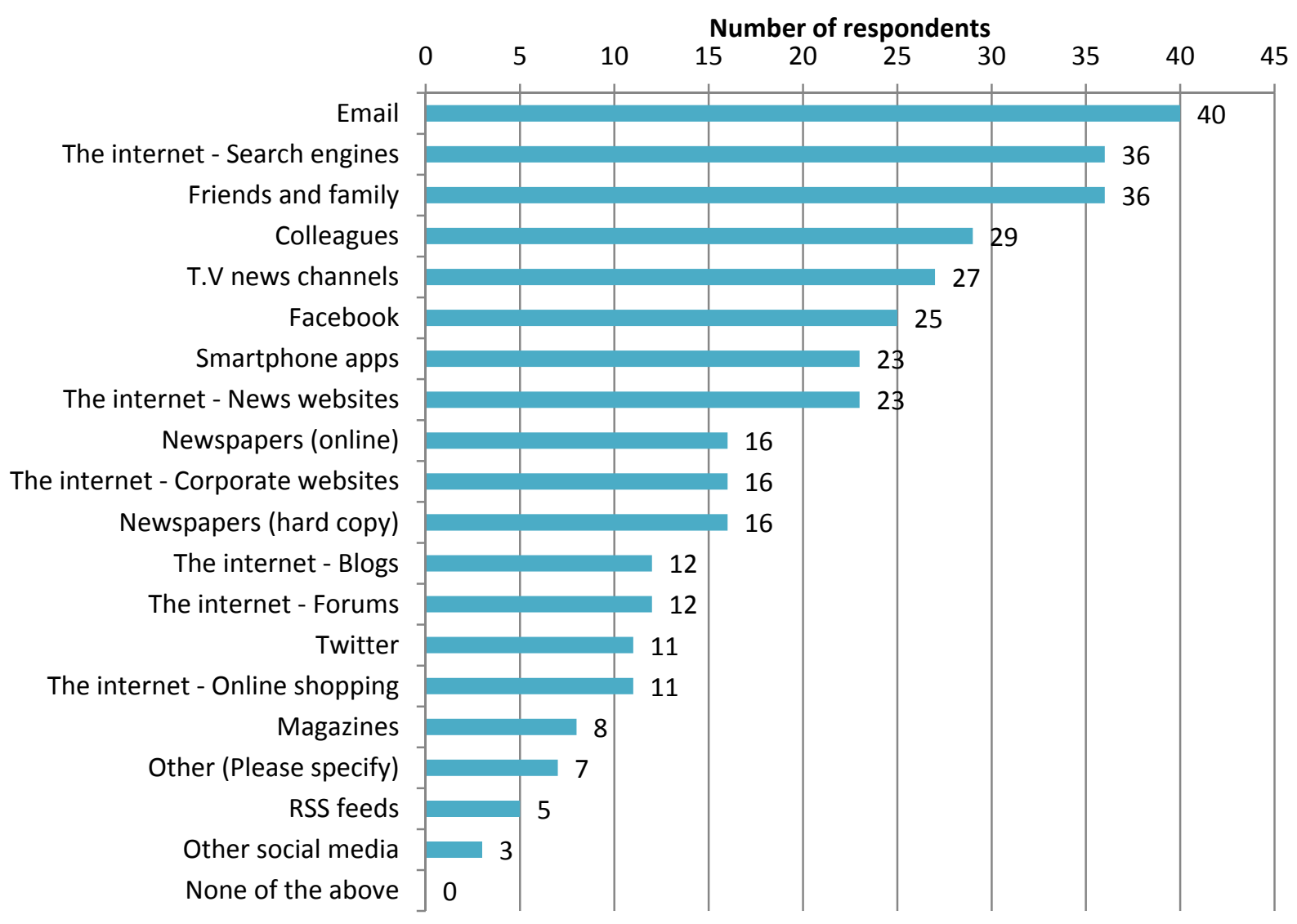

Figure 8 - Sources of information used on a daily basis

There is a general correlation between age and likelihood of using non-computer based sources. Only two of the over 70s use search engines and only one of these uses email; both of these tools are used by the vast majority of all other age groups. This age uses mainly paper-based sources or personal contacts.

Twenty nine of the study participants own a smartphone or table and there is a clear relationship between age and ownership. As expected, social media and blogs, or Web 2.0 services are more popular among the younger participants.

There was overall agreement that emails interrupt the completion of tasks and dealing with them takes a lot of time. One of the interviewees thinks that firm-wide guidance and protocols on emails would help reduce their volume while another interviewee discussed their experience in a library when computers were first introduced. "There were a lot of 
training programmes put in place to help older people learn computer skills...and I think older people who haven't had an opportunity will still find it difficult."

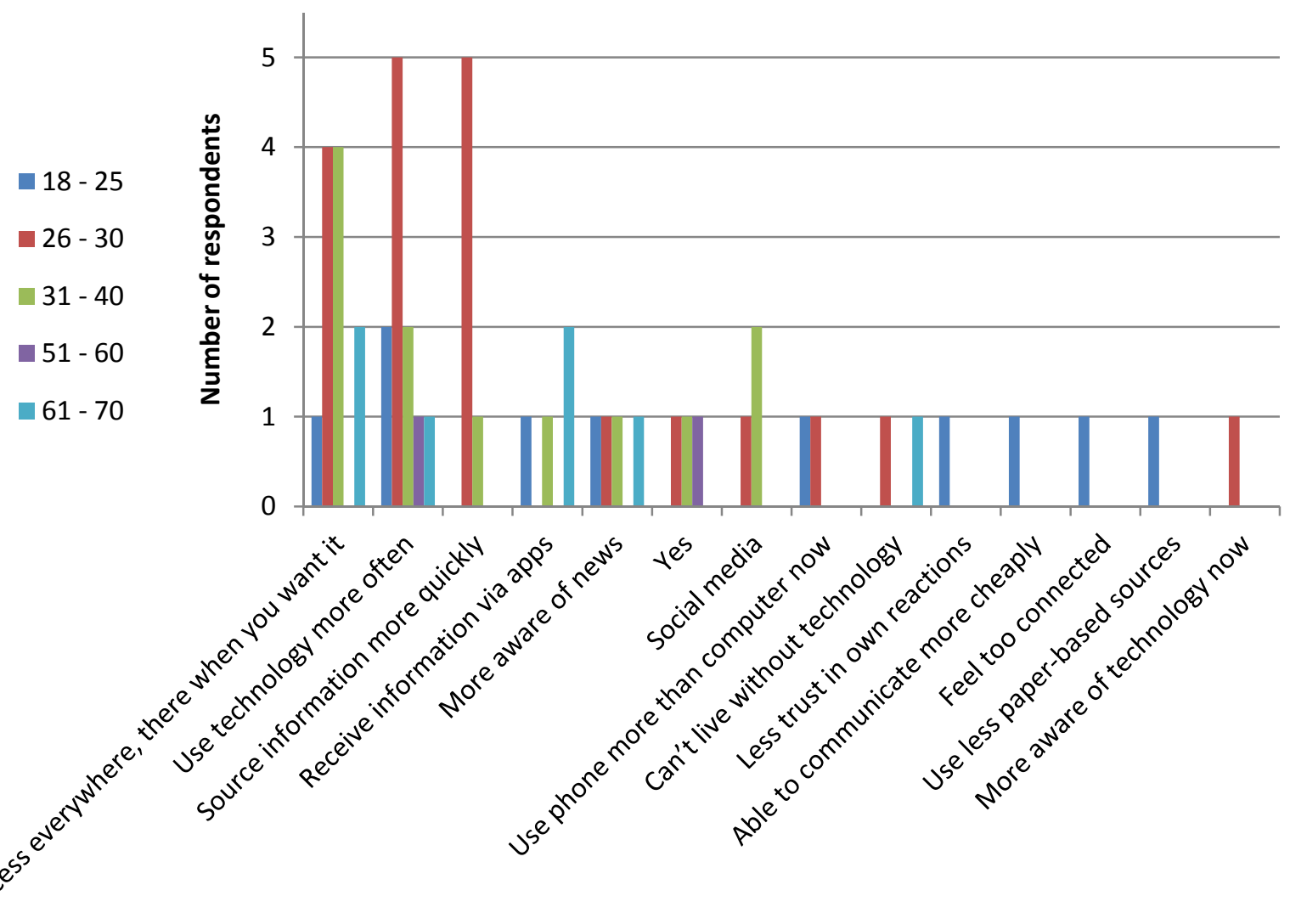

Figure 9 - Changes in interaction with information

The changes in interaction shown in Figure 9 imply that technology has become the primary focus of information usage due to its speed and ease of use. The interviewees also noticed changes in their interaction with technology - one of them cited smartphones as the cause for the change, "the fact you can access information anytime, anywhere." Another noticed that they now use the internet as their first port of call for information whereas five or ten years ago they may have used a reference.

When separated from information, there is an upwards trend among all the ages: the longer they are without information, the more anxious they feel. The results from the interviews concur that people would be unwilling to go without the use of technology, in particular the internet. One interviewee stated emphatically that they could not live without technology "not now we've had it so long" although the rest did make comments regarding how difficult life would become and that they would not choose to do so. 


\section{Discussion}

Seven themes have emerged from analysis of the empirical data and now frame the discussion:

\section{Definition of information overload}

There is no one single definition of information overload agreed upon in the literature (Jackson and Farzaneh, 2012; Bawden et al., 1999); this is something that is supported by the number of unique definitions gathered in this study. The majority of definitions bear a resemblance to the literature concentrating predominantly on processing ability, speed of information and the effects of technology (Wilson, 1995; Jacoby, 1977; Misra and Stokols, 2012). The role of technology was discussed most frequently in the definitions from the older age groups suggesting a possible link between age and perceptions of causes of information overload.

This study found that, apart from the oldest group, all ages were equally likely to have thought to have suffered from information overload. This could be due to use of technology or a link with job role. Web 2.0 could be responsible for the mention of speed of information and having no time to reflect or absorb among the younger age groups. Web 2.0 and social media allow instant and unlimited updates. It could also indicate that information literacy levels are not advanced among younger people.

The findings from the study indicate that information overload has become a commonly felt phenomenon with a wide range of professions suffering from it. However, the literature tends to focus on the workplace as a whole rather than focusing on the skills required in certain jobs and whether these might have any impact. This research found the possibility of a link between work experience and information overload: working as an administrator was a common link amongst those who had never suffered from it. Skills gained in an administration role such as dealing with high volumes of emails, maintaining file systems and multi-tasking other responsibilities are vital in avoiding information overload. The presence of information overload among the librarians who took part in this research indicates that skills learned are more important than job sector. If further research identified a strong link between workplace skills and information overload, this could have significant implications for organisations. The distribution of information and the design of training courses could be altered to reduce its effects. 


\section{Workplace overload}

Over half of respondents claimed to feel overload most often in the workplace. A large number of studies have been carried out investigating organisational information overload (eg Butcher, 1995; Meglio and Kleiner, 1990; Spira and Burke, 2009) while Reuters research (2000) discussed the effects of changes in society and workplace downsizing on an organisation.

One of the major problems arising from information overload is impaired performance with the results of this study finding that eight of the effects of information overload relate to this in some way. Low work efficiency is a result found throughout the literature and confirmed by the results of this study where it was found to be affecting people of all ages, but was mentioned most often by the $61-70$ age group. This group has seen the introduction of technology as an increasingly central component of the work day. A lack of, or reduced, skill with this technology may be an important actor and in turn reduce productivity. Regular training and guidance would combat this and be extremely beneficial in reducing information overload, thus improving productivity and job satisfaction rates.

Workplace pressure regularly featured as a cause of IO among all working age participants. The work/life balance of the 51 - 60 year olds was the most likely to be unhealthy and this group are most likely to be employed in managerial roles. This finding supports the Reuters research on 10 in managers: almost two thirds stating that their leisure and social activities had been affected by IO (Waddington, 1998). This suggests that older employees may benefit from increased support in the use of technology.

Stress featured heavily in the literature as a consequence of information overload but was rarely commented upon by study respondents and, when it was, there was no pattern regarding age. This could suggest that information related stress has decreased, that people feel other effects more strongly or that they have developed coping mechanisms and are not brought to the point of stress.

Misra and Stokols (2012) found that increased use of technology in the workplace has led to increasingly fragmented routines. This study confirmed this: low efficiency and distraction were highly rated effects from all ages and all but the youngest age group believe their concentration levels have decreased. Email is the key cause of these distractions and plays a major part in workplace overload.

Email was found to be both the most commonly used source of information among participants of this study and a highly ranked cause of IO. Training and guidance in email 
protocol emerged from the interviews as a way to reduce IO adding support to Jackson et al. (2006) when they state that providing training in the most effective use of email saves an employee time, thereby increasing productivity.

\section{Access to technology}

In the review of the literature, no studies investigated the link between age, access to technology and perception of information overload. This research found that there is a correlation between age and technology use: the older a person is, the less likely they are to use technology based sources of information. This is consistent with Goodman et al. (2003) who found that internet and email use decline with age. This could be due to lack of access to computers or lack of inclination. It is not unexpected to see that those in the older age groups use technology less often than the younger ones, when less than half of the over 60s in the UK are online (Grossman, 2011).

The over 70s who had never suffered from information overload do not interact with internet based technology but, instead, prefer to use newspapers, television and personal contacts. These are all mediums that permit a greater level of control than for example, the internet and email. Even amongst those older people who did experience information overload, the effects were felt less than in younger ages. These findings support Levy (2008) and Eppler and Mengis (2004) in the assumption that technology is not only a major cause of information overload but has exacerbated its effects. They also highlight the factor of control over information helping to reduce overload.

A good way to diminish these effects could be through the use of training. The positive effects of training older people in computers were discussed in the interviews and would lead to more skills in information searching and management.

\section{Information literacy}

Increasing ease of access to information was commonly cited in this research and that of Bawden et al. (2000). The shift in dynamic from the professional to the individual now carrying out information searches can lead to overload when searching is done by those not skilled in recognising valuable information quickly (Bawden et al. 1999), i.e. the information illiterate.

Information literacy is defined as "knowing when and why you need information, where to find it, and how to evaluate, use and communicate it in an ethical manner" (CILIP, 2013). This research found the majority of people feel confident in their ability to filter information while control over information was found more often in the younger age groups. This could 
be because of the preponderance of information to come in digital formats. The young also expressed the most confidence in their ability to use search engines effectively. These results are in contrast to the earlier finding that the young are most overwhelmed and stressed by information. The results are also in contrast to Rowlands et al. (2008) who discussed the 'Google generation' or those born after 1993, as having an alarmingly low level of information literacy and difficulty searching for information. This rather contradictory result could be because the youngest participants in this research were born in 1995 and were very few in number. These questions also relied on self-perception of skills.

A lack of information literacy among society has become a growing concern in the research literature in recent years. Rowlands et al. (2008) found that the use of physical libraries has declined and the internet, in particular search engines, has become the natural first place to look for information among young people, a fact reiterated in the interviews.

The findings of this study do not prove conclusively that information literacy is a major concern in young people although there was consensus within the interviews that improved information literacy would reduce information overload. This is consistent with Goulding's (2001) assertion that information literacy is often seen as the cure. The importance of training was discussed in the interviews; improved skills will empower people in their information use. This suggests that information overload is caused by lack of understanding of how and where to search for information and is an issue to resolve.

\section{Quantity vs. quality of information}

Abundance of information has been cited as a cause of information overload (Edmunds and Morris, 2000), a fact corroborated by this research; quantity of information topped the list of causes of information overload in the questionnaire. The rapid increase in information has been called the 'information explosion' and is described as "an extreme increase in the supply of information available" (Rudd and Rudd, 1986: 304). Figure 10 provides an illustration of what Kitsuregawa and Nishida (2010) call the 'info-plosion'. 


\section{infolplosion}

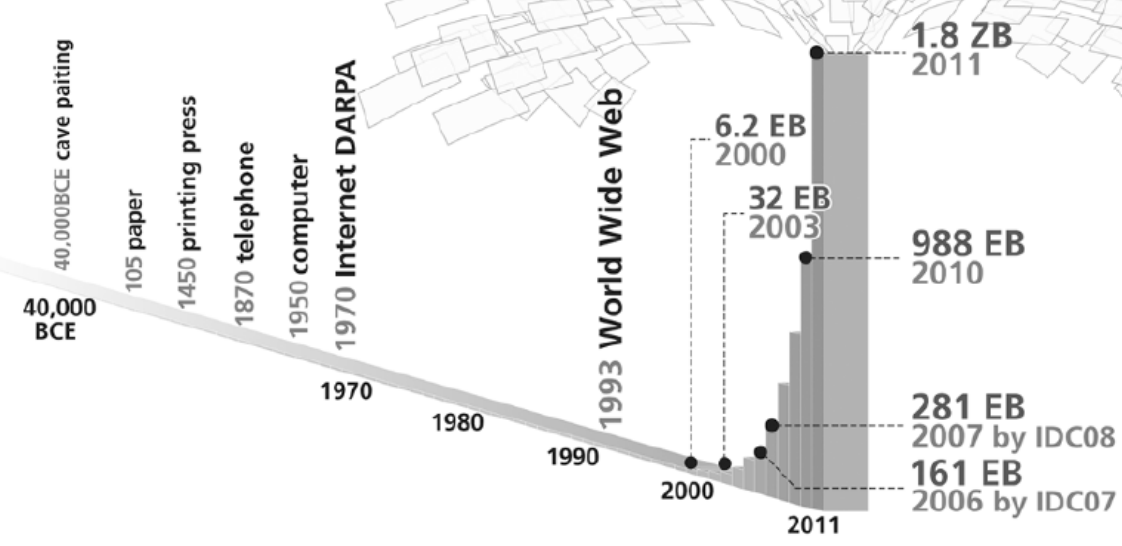

Figure 10- Info-plosion, Kitsuregawa and Nishida (2010, p. 208)

All age groups expressed concern about quantity of information but it was the youngest age that expressed the most difficulty in dealing with large quantities of information. This suggests tha,t despite having grown up with computers and the internet (Cabral, 2011), their information management and searching skills are not as advanced as those of older people. This could be a result of the predominance of search engines in searching for information.

There is debate in the literature over quality of information now available (Berghal, 1997; Bawden et al. 2000) which was also evident in this research. Conflict of opinion emerged frequently in the questionnaire, especially among the younger ages, and in the interviews it became apparent that knowing what sources can be trusted is increasingly difficult with the advent of Web 2.0 is largely to blame. This supposition gains weight with the knowledge that 26 - 30 year olds were found to be the highest users of Web 2.0 and also the group with the most trust issues regarding quality of information. Similarly, Bawden and Robinson (2009) expressed concern over Web 2.0 and quality.

Difficulty recognising quality information can make some daily activities more taxing and can have serious implications when carrying out research or academic exercises.

\section{Web 2.0}

There was agreement in the research that the increased use of blogs, personal websites, Wikipedia and social media can contribute towards information overload, a conclusion also 
drawn by Bawden and Robinson (2009). These sources can be grouped together under the term Web 2.0.

That young people experienced difficulty retaining and reflecting on information is consistent with Misra and Stokols (2012) who found that those who experience technology based overload have less time to spend in contemplation. The results of this study found a distinct correlation between age and technology use indicating potential for a growth in the lack of understanding of information among the young.

The nature of Web 2.0 means that information is now created and shared at a much quicker pace than ever before and allows people to keep up to date and communicate with friends quickly and easily. The fact that people feel pressure to do this emerged from this study and confirms Cabral's (2011) findings that the internet is used primarily for communication among the under 30s. Web 2.0 use is rising and has changed the way we view information. People are accustomed to and expect to be able to interact with information and the changing nature and non-permanence of this could create issues of overload or addiction in the future.

\section{Dependency on technology}

An increased reliance on technology as a means of information sourcing and sharing emerged from the research. Checking for social media updates, new emails and news items has increasingly become a habit rather than a conscious desire. The information explosion, the rise of Web 2.0 and easier access to information via technology are all leading towards an inevitable rise in information addiction: "we are so insatiably curious that we gather data even if it gets us in trouble" (Yoffe, 2009: 1).

Most respondents in this study rely on technology for information gathering and experience increasing anxiety the longer they are without information. Cabral (2011) found an increasing addiction to social media among young people, a finding supported in some measure by this study. Research into social media addiction is at its early stages, with research into information addiction virtually non-existent. Internet addiction has long been recognised as a problem in some Asian countries but is becoming more prevalent in the West (Neporent, 2013).

These findings have important implications for the future of information use and could point towards a shift in information pathologies: from overload to addiction. More research into this area is necessary to investigate whether young people are more likely to become addicted 
and what this would mean for information overload. Will it cease to exist or just manifest itself in different ways?

\section{Conclusion}

This study investigated the differences in perception between different ages towards information overload. While age was not found to be a factor in definitions of the concept, there was a correlation between age and technology use which resulted in lower rates of information overload among the older ages. Technology has been found to be a primary cause of information overload with emails being one of the main culprits, especially within the workplace. Time pressures and volume of email can cause low work efficiency. This was seen across all ages but was especially noted by older participants. Email overload, information overload and reduced productivity can have major implications for an organisation.

This study looked at the way our interactions with information have changed and found that technology, in particular mobile phones, is causing people to interact with information more regularly. This is primarily a habit of the younger ages thanks to their reliance on technology for information sourcing and heavy use of Web 2.0 services such as social media. This reliance has not yet turned into dependency or addiction but the study found signs that this may become a possibility in the future.

It was also shown that there is a difference in the way young people view information compared to older people. Due to their exposure to internet-based technology, young people expect to be able to interact with the information they view. It comes increasingly quickly and is fast changing; static, paper-based sources such as books are being used less and less by young people.

The rise of technologies such as Web 2.0 is largely to blame for the massive increase in information seen over recent years. With the rise of information abundance and availability questions of quality have also arisen. Quality of, and trust in, information is becoming a big issue especially among the younger ages. This study found that young people may be affected by lower levels of information literacy which causes them to feel overloaded. Skills in searching for and managing information are very important in overcoming this problem so a solution may be the increase of information literacy.

Another significant finding to emerge from this study is a possible link between job skills and information overload. For most people, information overload is the result of a lack of skills; but certain jobs, for example, administrators report lower instances of overload suggesting 
that they must have key skills and competencies. Identifying these skills and teaching them to others would go a long way towards reducing information overload.

Although this study is based on a small sample of participants, its findings suggest that a link between age and information overload does exist. Older people are less likely to suffer information overload due to lower technology use, whilst young people may be affected by reduced information literacy rates and an increasing reliance on technology. This research adds to the existing literature by providing an investigation into the effect of age on perceptions of information overload. Most research has looked into causes, effects, solutions and setting but has largely ignored the factor of age. By investigating this aspect, this study has shown that age does have an impact on information overload and could usefully be borne in mind when considering approaches to minimise its negative effects.

\section{Bibliography}

Ackoff RL (1967) Management misinformation systems. Management Science. 14(4): 147 156.

Alaszewski A (2006) Using Diaries for Social Research. London: Sage Publications.

Allen DK and Shoard M (2005) Spreading the load: mobile information and communications technologies and their effect on information overload. Information Research: An International Electronic Journal, 10(2): 227.

Bawden D and Robinson L (2009) The dark side of information: Overload anxiety and other paradoxes and pathologies. Journal of Information Science, 35(2): 180 - 191.

Bawden D, Devon TK and Sinclair IW (2000) Desktop information systems and services: a user survey in a pharmaceutical research organisation. International Journal of Information Management, 20(2): $151-160$.

Bawden D, Holtham C and Courtney N (1999) Perspectives on information overload. Aslib Proceedings: New Information Perspectives, 51(8): 249 - 255.

Bell J (2010) Doing Your Research Project. Berkshire: Open Press University.

Berghel H (1997) Cyberspace 2000: dealing with information overload. Communications of the $A C M, 40(2): 19-24$.

Boulding K (1966) The ethics of rational decision. Management Science, 12(6): $161-169$. 
Bush V (1945) As We May Think (an article that appeared in The Atlantic Monthly in 1945 predicting the electronic revolution). Available at:

http://quod.lib.umich.edu/j/jep/3336451.0001.101/--as-we-may-think-an-article-thatappeared-in-the-atlantic?rgn=main;view=fulltext;q1=vannevar+bush (accessed 20 July 2013).

Butcher H (1995) Information overload in management and business. In: IEE Colloquium on Information Overload, London, 1995, pp. 1/1 - 1/2.

Cabral J (2011) Is Generation Y addicted to social media? The Elon Journal of Undergraduate Research in Communications, 2(1): 5 - 14.

Carr N (2010) The Shallows. New York: Norton and Company, Inc.

CILIP (2013) Information literacy. Available at: http://www.cilip.org.uk/cilip/advocacy-awardsand-projects/advocacy-and-campaigns/information-literacy (accessed 3 September 2013].

Edmunds A and Morris A (2000) The problem of information overload in business organisations: a review of the literature. International Journal of Information Management, 20(1): $17-28$.

Elwert S (2013) Information overload making your head explode? Available at: http://www.wnd.com/2013/01/information-overload-making-your-head-explode/ (accessed_15 August 2013).

Eppler MJ and Mengis J (2004) The concept of information overload: a review of literature from organization science, accounting, marketing, MIS, and related disciplines. The Information Society, 20(5): 325 - 344.

Frazer L and Lawley M (2000) Questionnaire Design and Administration. Milton: John Wiley \& Sons.

Goodman J, Syme A and Eisma R (2003) Older adults' use of computers: a survey. In: Proceedings of HCl 2003: Designing for society, Bath, September 2003, pp. 25 - 28.

Goulding A (2001) Information poverty or overload? Journal of Librarianship and Information Science, 33(3): 109 - 111.

Gross BM (1962) Operation basic: the retrieval of wasted knowledge. Journal of Communication, 12(2): $67-83$. 
Grossman W (2011) Helping older people online. Available at:

http://www.bbc.co.uk/blogs/webwise/2011/11/helping-older-people-online.shtml (accessed 29 August 2013).

Hemp P (2009) Death by information overload. Available at: http://hbr.org/2009/09/death-byinformation-overload/ar/1 (accessed 23 January 2013).

HSE (2013) What is stress? Available at:

http://www.hse.gov.uk/stress/furtheradvice/whatisstress.htm (accessed 10 August 2013).

Jackson TW and Farzaneh P (2012) Theory-based model of factors affecting information overload. International Journal of Information Management, 32(6): 523 - 532.

Jackson TW, Burgess A and Edwards J (2006) A simple approach to improving email communication. Communications of the ACM - Hacking and innovation, 49(6): 107 - 109.

Jacoby J (1977) Information load and decision quality: some contested issues. Journal of Marketing Research, 14(4): 569 - 573.

Jacoby J (1984) Perspectives on information overload. Journal of Consumer Research, 10(4): $432-435$.

Karvalics L (2007) Information society - what is it exactly? (The meaning, history and conceptual framework of an expression. Available at:

http://www.msu.ac.zw/elearning/material/1349116439Information-Society-whatis.pdf (accessed 31 January 2013).

Kitsuregawa M and Nishida T (2010) Special issue on information explosion. New Generation Computing, 28: 207 - 215.

Latane B (1978) Journals do not cause- they solve the problem of information overload. Personality and Social Psychology Bulletin, 4(4): 514 - 514.

Levy DM (2008) Information Overload. In: Himma K, Herman T (eds) The Handbook of Information and Computer Ethics. New Jersey: John Wiley \& Sons, Inc, pp. 497 - 515.

Lewis D (1996) Dying for information. Available at:

http://www.thefreelibrary.com/New+Independent+Research+Reveals+Cost+of+the+Informati on+Revolution-a018769373 (accessed 23 January 2013). 
Malhotra NK, Jain AK and Lagakos SW (1982) The information overload controversy: an alternative viewpoint. The Journal of Marketing, 46(2): 27 - 37.

Meglio CE and Kleiner BH (1990) Managing information overload. Industrial Management and Data Systems, 90(1): 23 - 25.

Meier RL (1962) A Communications Theory of Urban Growth. Cambridge, MA: M.I.T. Press.

Michalos A (1974) Strategies for reducing information overload in social reports. Social Indicators Research, 1(1): 107 - 131.

Miniwatts Marketing Group (2013) Internet world stats. Available at: http://www.internetworldstats.com/stats.htm (accessed 31 January 2013).

Misra S and Stokols D (2012). Psychological and health outcomes of perceived information overload. Environment and Behavior. 44(6): 737 - 759.

Neporent L (2013) Hospital first in US to treat internet addiction. Available at: http://abcnews.go.com/Health/hospital-opens-internet-addiction-treatmentprogram/story?id=20146923\&singlePage=true (accessed 10 September 2013).

Noyes JM and Thomas P (1995) Information overload: an overview. In: IEE Colloquium on information overload, London, November 1995 pp. 1 - 3.

Reeves R (2002) Reality bites. Available at:

http://www.managementtoday.co.uk/news/407519/Reality-bites/?DCMP=ILC-SEARCH (accessed 23 January 2013).

Reuters (2000) The Reuters guide to good information strategy. Available at: http://jmab.planetaclix.pt/GesInf/Aula5/The_Reuters_Guide_to_Good_Information_Strategy. pdf (accessed 10 August 2013).

Rowlands I, Nicholas D, Williams P et al. (2008) The Google generation: the information behaviour of the researcher of the future. Aslib Proceedings: New Information Perspectives, 60(4): $290-310$.

Rudd MJ and Rudd J (1986) The impact of the information explosion on library users: overload or opportunity? Journal of Academic Librarianship, 12(5): 304 - 306.

Soucek R and Moser K (2010) Coping with information overload in email communication: evaluation of a training intervention. Computers in Human Behavior, 26(6): 1458 - 1466. 
Spira, J.B., and Burke, C., 2009. Intel's war on information overload. Available at: http://iorgforum.org/wp-content/uploads/2011/06/IntelWarlO.BasexReport1.pdf (accessed 31 January 2013).

Stickel C, Holzinger A and Ebner M (2008) Useful oblivion versus information overload in elearning examples in the context of wiki systems. In: 30th International Conference on Information Technology Interfaces, 2008, pp.171 - 176.

Szóstek AM (2011) 'Dealing with my emails': latent user needs in email management. Computers in Human Behavior, 27(2): 723 - 729.

Tildine TJ (1999) The mythology of information overload. Library Trends, 47(3): 485 - 506. Waddington P (1998) Dying for information? A report on the effects of information overload in the UK and worldwide. Available at: http://old.cni.org/regconfs/1997/ukolncontent/repor 13.html (accessed 05 July 2013).

Waller A and Ragsdell G (2012) The Impact of e-mail on work-life balance. Aslib: New Information Perspectives, 64(2): 154 - 177.

Wellmon C (2012) Why Google isn't making us stupid... or smart. The Hedgehog Review. 14(1): $66-80$.

Wilson P (1995) Unused relevant information in research and development. Journal of the American Society for Information Science, 46(1): 45 - 51.

Wright KB (2005) Researching internet-based populations: advantages and disadvantages of online survey research, online questionnaire authoring software packages, and web survey services. Journal of Computer-Mediated Communication, 10(3): 1.

Yoffe E (2009) How the brain hard-wires us to love Google, Twitter, and texting. And why that's dangerous. Available at:

http://www.slate.com/articles/health_and_science/science/2009/08/seeking.single.html\#page break_anchor_2 (accessed 10 September 2013). 